\title{
UNA REFLEXIÓN TEÓRICA EN TORNO A LAS MIGRACIONES LABORALES, A TRAVÉS DEL CASO HISTÓRICO DEL PROGRAMA BRACEROS (1942-1964)
}

\author{
Alfonsina Verónica Albertí ${ }^{1}$ \\ Universidad Nacional de La Plata, CEIL-CONICET, Argentina \\ http://dx.doi.org/10.5209/rev_NOMA.2012.41785
}

Resumen: El presente artículo pretende realizar una reflexión en torno a cuales han sido los distintos factores que se han privilegiado para explicar el fenómeno de la migración laboral, desde distintas posturas teóricas, a través de la descripción de las migraciones laborales de mexicanos a Estados Unidos en el marco del denominado "programa braceros" vigente en el período temporal que va desde el año 1942 hasta el año 1964.

Palabras clave: migración laboral, México, Estados Unidos, programa braceros

\section{A theoretical reflection around the labor migrations, through historical case of the bracero program (1942-1964)}

\begin{abstract}
The present article tries to realise a reflection around as they have been the different factors that have been privileged to explain the phenomenon of the labor migration, from different theoretical positions, through the description of the labor migrations of Mexican to the United States within the framework of the denominated "Bracero program" in the temporary period that goes from year 1942 to year 1964.
\end{abstract}

Keywords: labor migration, Mexico, United States, bracero program

\section{Introducción}

El objetivo de este trabajo es generar una reflexión en torno a cuáles han sido los distintos factores, que han sido privilegiados para explicar el fenómeno de la migración laboral, desde diferentes posturas teóricas, a través de la descripción de un caso histórico concreto: Las migraciones laborales de México a Estados unidos en el marco del programa Braceros.

El "Programa Braceros" consistió en un acuerdo bilateral sostenido desde el año 1942 al año 1964 entre los gobiernos de México y Estados unidos, para establecer la contratación legal de trabajadores mexicanos principalmente hacia el empleo agrícola de este último país. Este programa debido a su dimensión y duración ha sido considerado un paradigma de los programas del empleo temporal.

\footnotetext{
${ }^{1}$ Licenciada en Antropología. Becaria doctoral del centro de estudios e investigaciones laborales (CEIL).
} 
En primer lugar, se brindara una breve exposición de algunas explicaciones teóricas en torno al fenómeno de la migración laboral, con el fin de proporcionar herramientas para la mejor comprensión del caso elegido.

Luego, se describirán los antecedentes de movilidad de mano de obra previos a las migraciones del programa braceros, contextualizados dentro de los procesos históricos que han sido relevantes en la conformación de estos flujos poblacionales.

En tercer lugar, se presentará la coyuntura histórica en la que dicho programa fue pautado, y algunas de las características particulares que presentó el mismo.

Por último y a modo de conclusión se pondrán en dialogo las distintas cuestiones teóricas referidas a las migraciones, expuestas al principio de este trabajo, con el caso histórico concreto de las migraciones laborales tratadas en el mismo.

\section{Algunas nociones teóricas en torno a las migraciones laborales}

El fenómeno migratorio laboral va mutando no sólo en términos de volumen de los flujos sino también en el significado social de los movimientos, así como también van cambiando las concepciones utilizadas para interpretar al mismo. Expondremos brevemente algunas de las explicaciones que han sido más utilizadas a la hora de caracterizar los procesos migratorios, sobre todo aquellas que aluden a los motivos que originan que estos desplazamientos se produzcan $^{2}$.

Arango (2003) nos relata que las primeras conceptualizaciones teóricas referentes a las migraciones en la década del 60 provinieran de la economía; la llamada explicación neoclásica constituía una traslación de los modelos de equilibrio dominantes en ese periodo: el predicado neoclásico en economía y el paradigma funcionalista en sociología.

Si se quiere resumir la teoría económica neoclásica tomando como asunción básica el punto de vista de Harris y Todaro (1970), se puede decir que la migración se explica en base a desequilibrios en los mercados de trabajo de las diferentes regiones. Debido a estos desequilibrios, los niveles de utilidad individual, normalmente operacionalizados en salarios, son diferentes en un lugar y en el otro, lo cual induce a los individuos que toman decisiones a emigrar a zonas con una mayor utilidad. La migración rectifica los desequilibrios, fundamentalmente los desequilibrios de los salarios. En consecuencia los modelos neoclásicos presentan a la movilidad del trabajo como un factor de progreso económico. Desde esta perspectiva las migraciones se tratan de un acto individual, espontáneo y voluntario basado en

\footnotetext{
${ }^{2}$ No se expondrán la totalidad de teorías en torno a las migraciones laborales, sino solo aquellas que se consideren más relevantes para proporcionar herramientas conceptuales a la hora de analizar el caso concreto de las migraciones laborales, que ocurrieron dentro del marco del Programa Braceros.
} 
la comparación entre la situación actual del actor y la ganancia neta esperada que se deriva del desplazamiento resultado de un cálculo coste-beneficio.

El análisis histórico- estructural conforma otra de las corrientes explicativas para la movilidad poblacional en el espacio, se considera que la misma no es un acto racional del individuo sino un fenómeno social donde la unidad de análisis es la corriente migratoria compuesta de clases o grupos socioeconómicos que son compelidos a trasladarse por estructuras sociales geográficamente delimitadas (Pachano, 1986).

Portes y Boroez (1998), exponentes de este tipo de explicación, nos relatan que el proceso migratorio no es considerado como la resultante de un conjunto de individuos que llevan a cabo elecciones racionales, sino como la resultante de desigualdades socio espaciales que se reproducen sistemáticamente. La emigración, como otros intercambios, no ocurre como un proceso externo entre dos entidades separadas sino como parte de la dinámica interna del sistema capitalista. En consecuencia para este enfoque, los desplazamientos lejos de ser flujos reequilibrantes, tienden a acrecentar las desigualdades regionales. Desde este punto de vista, las migraciones son vistas como un fenómeno interno a la economía mundo, como algo inherente al proceso secular de expansión de la economía capitalista, y no como un proceso externo de intercambio espontáneo entre Naciones Estado consideradas independientemente.

Otro tipo de explicación para los movimientos poblacionales es el planteo neoestructuralista de Gaudemar (1976), este autor afirma que existe una correlación positiva entre el grado de desarrollo económico alcanzado por un país y la movilidad de su fuerza de trabajo ${ }^{3}$. Al igual que Marx, concibe a la movilidad como una característica propia de la fuerza de trabajo, que potencialmente acrecienta la productividad, se relaciona con la afirmación y expansión física del capital y por lo tanto se expresa como condición y a la vez como consecuencia de las fuerzas productivas. El capital tiende a monopolizar y a extender el trabajo productivo a todas las esferas de la producción. Lo mismo ocurre con la mano de obra: el capitalismo crea la fuerza de trabajo y esa fuerza de trabajo es móvil. Por ello Gaudemar afirma que "toda estrategia capitalista de movilidad es una estrategia de movilidad forzada" (1976, pp17).

Este último autor, destaca la importancia de considerar la migración como fenómeno social históricamente determinado por el conjunto de relaciones sociales de producción, en la medida en que se presupone que la población no es una identidad abstracta, sino por el contrario, quienes participan de la movilidad son grupos o categorías sociales especificas que se ven afectadas por el proceso de cambio. A diferencia del pensamiento estructuralista tradicional, este autor amplía la nómina de variables causantes de la movilidad,

3 Con el termino movilidad Gaudemar se refiere al desplazamiento espacial entre distintas regiones integradas a la producción capitalista (movilidad geográfica) como así también a la movilidad sectorial ( transferencia de mano de obra de un sector económico a otro) y a la movilidad profesional o socio profesional ( reconversión de la mano de obra en el interior de un mismo sector económico: cambio de profesión, de categoría socio- profesional, de establecimiento) 
incluyendo además a los factores ecológicos, culturales, normativos y a los demográficos, porque considera la interrelación entre los cambios sociales y la dinámica demográfica.

Desde otro punto de vista, Gaudemar (1976) también resalta las posibilidades de intervención de los sujetos que participan de la movilidad y en su tesis da ejemplos de ciertos procesos que habían sido concebidos como histórica y estructuralmente determinados pueden ser modificados. En este contexto, una fuerza de trabajo móvil puede desarrollar estrategias de negación o contramovilidad a la lógica capitalista. En este sentido este planteo tiene una visión dinámica de la relación movilidad y territorio, por cuanto la migración puede tomarse en un elemento modelador del espacio.

\section{Antecedentes de la movilidad de mano de obra de México a Estados Unidos, previos al Programa Braceros}

Consideramos que la dinámica migratoria laboral de México hacia Estados Unidos, solo puede ser claramente comprendida, si se la contextualiza dentro de aquellos acontecimientos del proceso histórico que han sido relevantes en la conformación de estos flujos poblacionales. Por ello expondremos algunos sucesos históricos que han sido considerados importantes a la hora de explicar estos tipos de movimientos poblacionales.

Varios estudios- entre ellos los de López Castro (1986), y Verduzco (2000)parten de la anexión de los antiguos territorios septentrionales de México a Estados Unidos, perdidos durante el expansionismo estadounidense entre 1836 y 1853, para comenzar a hablar de los movimientos poblacionales, que comenzaron a constituir una primera red de contactos entre los mexicanos que se quedaron en Estados Unidos y aquellos que se repatriaron a su nueva tierra en México ${ }^{4}$.

Después de la anexión de California y otros estados a la federación estadounidense, se calcula que aproximadamente un $25 \%$ de la población mexicana residente en aquellos lugares pasó a vivir a territorio mexicano a fin de poder habitar en un ambiente más hospitalario. Sin duda alguna, estos primeros movimientos de población del ex territorio mexicano al norte del país fueron la ocasión para que se iniciara una primera red de contactos entre los mexicanos que se quedaron en Estados Unidos y aquellos que se "repatriaron" a su nueva tierra en México. Desafortunadamente no existen cifras que nos puedan dar indicios sobre el volumen o la intensidad de esos contactos, ya que los ingresos por tierra a la Unión Americana no fueron registrados sino hasta el año 1908 y sólo se cuenta con información suelta de periódicos y documentos de archivos.

Ya desde fines del siglo XIX los estadounidenses viajaban al centro y occidente de México, con el fin de reclutar trabajadores para las labores de construcción

\footnotetext{
${ }^{4}$ Antes que se produjese la invasión estadounidense a México, este último tenía parte de su territorio en lo que hoy en día son los actuales Estados de California, Utah, Colorado, Arizona, Nuevo México y Texas.
} 
de ferrocarriles, así como para las necesidades de la industria que se iniciaba en la región de Chicago y sus alrededores. Para 1909, por ejemplo, los mexicanos constituían $17 \%$ de la fuerza laboral, dedicada al mantenimiento de las líneas ferroviarias más importantes, y $10 \%$ de las cuadrillas de trabajadores en los estados del suroeste.

Durante el Porfiriato ${ }^{5}$, el proceso de desarrollo de México, impulsado por el dinamismo de la demanda externa y de las inversiones extranjeras en la explotación minera y en la inversión de una estructura de ferrocarriles que liga México con Estados Unidos, se vinculó de forma importante con el exterior. Durante esta época los empleadores estadounidenses viajaban al centro y occidente de México con el fin de reclutar trabajadores para la construcción de ferrocarriles. Hacia 1908 los trabajadores mexicanos llegaron a representar un $70 \%$ de la cuadrillas de trabajadores de las líneas férreas (López Castro,1986).

A partir de estos hechos podemos apreciar la importancia que tuvieron las migraciones laborales mexicanas hacia Estados unidos, ya desde finales del siglo XIX y principios del XX. De hecho el primer acuerdo bilateral referente a la migración laboral del que se tenga noticia data del año 1909, cuando el presidente mexicano Porfirio Díaz y presidente estadounidense William Taff, firmaron un convenio para la exportación de 1.000 trabajadores que debían ir a laborar a los campos de Betabel, una industria considerada como prioritaria para el gobierno de Estados Unidos, dada la ausencia de clima adecuado para la producción de caña de azúcar. Estos primeros braceros se habrían dirigido al sur de California (Durand, 2007).

Entre 1911 y 1921, México tuvo una pérdida demográfica de 2,7 millones de personas debido al conflicto armado revolucionario, frente a una población esperada de 17 millones, es decir el faltante alcanzaría al 16\% de la población. Sin embargo además del inicio del conflicto armado en México, también influyó como factor de atracción en Estados Unidos, la naciente demanda de trabajadores agrícolas debido del involucramiento de ese país con la primera guerra mundial, así como el fin de la importación de mano de obra japonesa a partir de 1907 y después las de otros lugares de Asia a partir de 1917 (Kelly, 1983).

En 1917 se promulgó en Estados Unidos la ley migratoria conocida como Burnett, la misma limitaba la entrada de inmigrantes a Estados Unidos mediante restricciones como el pago de ocho dólares y que los mayores de 16 años demostraran que sabían leer y escribir. Esta ley, tenía como propósito detener el flujo de migrantes analfabetos que provenían del este y sur de Europa y que huían de la primera guerra mundial, pero esto afectó a los trabajadores migrantes mexicanos, que por lo general no podían cubrir el requisito de alfabetización y menos aún pagar una cuota de ocho dólares. El resultado fue la deportación sistemática de mexicanos y mayores dificultades para cruzar la frontera de forma legal. Esta ley apareció en una pésima

\footnotetext{
${ }^{5}$ Por Porfiriato se entiende la etapa transcurrida de 1876 a 1911, caracterizada por el gobierno de Porfirio Díaz, que se vio interrumpida entre 1880 y 1884 por la presidencia de Manuel González.
} 
coyuntura, justo antes de que Estados Unidos ingresara a la primera guerra mundial, el dos de abril de 1917, y que se manifestara, por una escasez de mano de obra y por otra una mayor demanda de la misma (Cardoso,1980).

En mayo de de 1917, se promulgó una excepción para aquellos que fueran trabajadores temporales y que se dedicaran exclusivamente al trabajo agrícola, es decir los Mexicanos. De este modo las leyes, disposiciones y excepciones fueron conformando un flujo de inmigrantes mexicanos que se caracteriza por ser una mano de obra temporal y por dedicarse prioritariamente a la agricultura. Este modelo sería reajustado y perfeccionado posteriormente durante el programa Bracero.

Para 1921, debido a una nueva legislación en Estados Unidos que restringió fuertemente la inmigración europea, está circunstancia favoreció el uso de la cercana mano de obra mexicana. Encontramos así que entre 1921 y 1930, la inmigración mexicana aumentó el doble que la generación anterior. El número de mexicanos aceptados solo fue superado por el de los canadienses y casi fue igual, aunque superior, al de alemanes e italianos (Verduzco 2000).

Durante la época de la depresión económica de 1929, mostró claramente un fenómeno que probablemente no era nuevo y que se repetiría ulteriormente, por una parte se produjo un estancamiento y detenimiento de la corriente migratoria y por otra, se puso en marcha un proceso de expulsión y repatriación de emigrantes previos, incluso de aquellos con potenciales derechos de residencia. De 1930 a 1933 se estima que regresaron a su país alrededor de 300.000 mexicanos (Diez Canedo Ruíz, 1984).

Más tarde, si bien el reparto agrario realizado por el presidente Cárdenas (1935-1940), que alcanzó casi 20 millones de hectáreas, detuvo parcialmente la migración, la concentración de inversiones productivas en estados escasamente poblados del norte, así como la institucionalización del programa Bracero en 1942, se convirtieron en alternativas que incrementaron la movilidad geográfica de la población (Stern, 1989).

Es importante señalar que el proceso de urbanización comenzó a acelerarse a partir de 1940. Esto se observa cuando se comparan los crecimientos poblacionales en el sector rural y en el urbano con relación a la población total, la población total se triplicó de 1930 a 1970, mientras que la población rural (de localidades de menos de 2500 habitantes) sólo se duplico, la urbana (de 15.000 y más habitantes) se incrementó más de diez veces. El principal factor de este cambio fue la migración de las ciudades pequeñas y medianas a las grandes metrópolis (Verduzco, 2000).

\section{El programa Bracero: contexto de emergencia y características}

Hacía el año 1941, luego del ataque japonés A Pearl Harbor, Estados unidos se involucra más fuertemente en la segunda guerra mundial, la cuál había estallado en 1939, y comienza a combatir no solo contra Japón sino también contra Alemania e Italia, esto afectará de algún u otro modo a todos los países 
latinoamericanos. Estados Unidos exigía compromiso con la causa Aliada, abriendo una mayor ayuda económica a los países de Latinoamérica a cambio de solidaridad y apoyo a sus necesidades estratégicas, en el contexto de la guerra.

En ese entonces la industrialización se convirtió en el rasgo central de la política económica mexicana de Ávila Camacho, sucesor de Cárdenas y ex secretario de guerra del mismo, cuando asumió el poder en el año 1940, y más tarde su sucesor, el presidente Miguel Alemán, continúo con la misma política durante los años de 1946 a 1952.

La segunda guerra mundial significó para América Latina, un crecimiento abrumador por parte de Estados Unidos sobre sus naciones. En el caso particular de México, la transformación de las relaciones con Estados Unidos fue tan completa que ya en 1942 el ministro de asuntos exteriores mexicano describía la frontera como una línea de unión no de división. Observaciones como estas resultan asombrosas si se tiene en cuenta el encarnizado enfrentamiento por el petróleo ocurrido entre ambos países solo cuatro años antes. (Bulmer-Thomas 1997).

Meyer (2000) nos relata que la contribución mexicana más efectiva al esfuerzo bélico de los aliados no fue de orden militar sino económico. En virtud del tratado de comercio de 1940, una comisión de México y Estados Unidos ideó planes de producción y fijó los precios de las materias primas que México enviaría a su vecino del norte, minerales más productos agrícolas, y se estableció también el programa de braceros para contribuir a remediar la falta de mano de obra agrícola en Estados Unidos como consecuencia de la guerra.

El programa bracero facilitó el acceso de mano de obra de bajo costo a los productores norteamericanos, principalmente de California y Texas. El mismo reclutó un total de cinco millones de trabajadores para laborar prioritariamente en el sector agrícola, en los ferrocarriles o en el sector minero. Se trató de un modelo de migración pensado exclusivamente para hombres, que exigía un modelo de varón joven, soltero de origen rural, dedicado al medio rural; a quien se le proponía una contratación temporal (Durand y Arias, 2005).

Los antecedentes inmediatos al programa Bracero fueron el sistema de contratación temporal conocido como el "libre enganche", que funcionó exclusivamente en el Estado de Texas. En el sistema de libre enganche los trabajadores mexicanos viajaban en forma familiar y por temporadas, con el objetivo de trabajar, ahorrar y regresar al pueblo. En este programa el modelo de contratación era el grupo familiar. Modelo que así como garantizaba la mano de obra a los patrones norteamericanos en el sector agrícola y los ferrocarriles, para el gobierno significaba el temor de que las familias se quedaran a vivir en territorio americano. Si bien los trabajadores podían circular de un campo a otro, las oficinas de contratación o "centros de enganche" estaban centralizados en San Antonio. Los productores privados se trasladaban a San Antonio, Texas, para la contratación de los jornaleros (Orrenius y Zavodny, 2003) 
Para muchos autores, incluso críticos como Carey McWilliams (1954) y Galarza (1964) ${ }^{6}$ el programa bracero tuvo notables ventajas, sobre todo, si se le compara con la situación anterior del "libre enganche" lo que generó un cambio radical en el patrón migratorio, así la contratación dejó de ser un negocio particular y pasó a depender de programas oficiales de carácter bilateral. El programa bracero inaugura un nuevo período en la historia de la migración México-Estados-Unidos, transformando radicalmente el patrón migratorio que deja de ser familiar, de larga estancia y dudosa situación legal, para transformarse en un proceso legal, de origen rural, masculino y orientado hacia el trabajo agrícola. Así las migraciones pasaron a ser de carácter no permanente, es decir temporales. ${ }^{7}$

Durand (2007) realiza un balance crítico en torno al programa bracero, poniendo énfasis a las ventajas y desventajas del mismo, dentro de las ventajas más sobresalientes podemos mencionar:

- $\quad$ El reconocimiento de la existencia de un mercado de trabajo binacional: una de las virtudes fue el reconocimiento explicito por parte de Estados unidos, de la existencia de un mercado de trabajo binacional. A diferencia de la mayoría de las leyes migratorias norteamericanas que son de aplicación general, el programa Bracero fue un acuerdo bilateral, promovido originalmente por Estados unidos y sostenido por el interés mutuo de ambas partes.

- Un cambio radical en el patrón migratorio: La primera virtud del programa bracero fue acabar con el sistema de enganche. La contratación dejo de ser un negocio particular y paso a depender de programas oficiales de carácter bilateral. El programa Bracero inaugura un nuevo período en la historia de la migración México- Estados Unidos, transforma radicalmente el patrón migratorio que deja de ser familiar, de larga distancia y dudosa situación legal, para convertirse en un proceso legal, masculino, de origen rural y orientado hacia el trabajo agrícola.

- La migración temporal como tipo ideal: Otra ventaja del programa Braceros fue su carácter temporal. Los trabajadores iban y regresaban. Este punto es fundamental, porque es un elemento de coincidencia plena de los dos gobiernos involucrados. México y Estados Unidos, incluso en la actualidad, están de acuerdo en que la migración legal, de tipo temporal, es una de las mejores opciones.

- Un programa de larga duración: el programa bracero funcionó a lo largo de 22 años. El programa se dio en el contexto de guerra pero fue tan exitoso que se prolongó durante veinte años más.

- Un programa acotado y flexible: se trató de un programa acotado. Pretendía solucionar la escasez de mano de obra en un campo específico del mercado: la agricultura. Pero al mismo tiempo fue un programa suficientemente flexible como para implementar el programa ferroviario de corta duración (19431945), porque el momento y las necesidades de mano de obra así lo requerían. Incluso se llevó a cabo un programa similar para el caso del trabajo en las

\footnotetext{
${ }^{6}$ Citados por Durand, 2007.

${ }^{7}$ Las migraciones temporales, llamadas también transitorias son aquellas en las que no se produce un cambio de domicilio permanente.
} 
minas. Es decir fue un programa limitado, pero a la vez pudo ser utilizado de manera creativa de acuerdo con las necesidades del momento

- Mejoras en las condiciones laborales y salariales: El programa bracero constituyó un avance sustancial en cuanto a las condiciones de vida y trabajo de los trabajadores migrantes. Se llegaron a formular acuerdos y disposiciones para garantizar condiciones mínimas de legalidad, contratación, vivienda, transporte y salario mínimo. La experiencia del programa Bracero fue retomada posteriormente en conferencias y acuerdos mundiales sobre los derechos de los trabajadores migrantes.

- Una maquinaría burocrática eficiente: El programa demostró en repetidas ocasiones ser una maquinaría eficiente. Llegó a movilizar entre 1954 y 1960 a un promedio de 350 mil trabajadores anualmente.

- $\quad$ Un programa costeable: el programa suponía una serie de gastos, para ambos gobiernos y para los empleadores. Pero a pesar de las quejas, esto no significó la quiebra de ninguna empresa, ni una escalada de salarios y precios de productos agrícolas. Distintos reportes de la época señalan que con el tiempo el programa fue superando dificultades y los empleadores empezaron a valorar sus ventajas y a cooperar para su buen funcionamiento

No obstante estas ventajas presentadas por el convenio, es de esperar que en realidad el mismo no haya sido una panacea a la situación de los trabajadores, si se tiene en cuenta que el trabajo migrante es por definición, el más duró, el más desgastante y el peor remunerado de la escala laboral. Duránd (2007) señala también una serie de desventajas del programa, entre las más destacadas podemos mencionar:

- La oferta mayor que la demanda oficial de braceros: una de las consecuencias negativas del programa braceros fue el movimiento paralelo de trabajadores indocumentados, que llegó a tener dimensiones semejantes. Obviamente el programa no satisfacía plenamente la demanda. Se calcula que en los veintidós años del programa Bracero ingresaron cerca de cinco millones de indocumentados a Estados unidos. La solución no era fácil para ninguno de los dos países. Para México era complicado políticamente hablando, duplicar el número de braceros y para Estados Unidos también. En realidad ambos gobiernos eran plenamente conscientes del problema, pero poco podían hacer al respecto. La única medida de excepción fue la deportación masiva con la operación Wetback, que tuvo como consecuencia un incremento notable en las contrataciones en los años siguientes

- Un convenio bilateral o un acuerdo obrero patronal: En segundo término habría que señalar la beligerancia de las partes y el carácter de fondo el convenio, que era de orden obrero-patronal. Cada año se negociaba una especie de "convenio colectivo de trabajo" y las partes lógicamente no se ponían de acuerdo. México amagaba con la "huelga", es decir se negaba a enviar trabajadores en esas condiciones y Estados Unidos contrataba a los trabajadores de manera unilateral o legalizaba a indocumentados. Estas tensiones contrastan con la facilidad con la que se llegó a un convenio en 1942 cuando se inicio el programa. El jaloneo de ambas partes y la falta de acuerdos razonables a mediano y largo plazo fueron, sin duda, un problema recurrente en la negociación anual bilateral. No obstante es necesario destacar que se pueden distinguir cuatro etapas en este proceso. Durante el primero y segundo 
años (1942-1943) estuvo a cargo del programa la Farm Security Administration, quien en años anteriores se había destacado por su apoyo incondicional a los trabajadores agrícolas y por propugnar una serie de mejoras, especialmente en la vivienda y en los campamentos. Pero en julio de 1943, la administración paso a manos de la Ward Food Administration y posteriormente a la oficina del trabajo. Finalmente en 1954 con la renegociación del convenio, el gobierno de Estados Unidos dejo de ser el contratante y pasó a estar a cargo de particulares, que por medio de asociaciones debían solicitar los contingentes de braceros. Este último cambio fue radical y dejó en peor situación a los trabajadores que se tenían que arreglar directamente con los patrones y el gobierno solamente supervisaba.

- Gastos trámites y burocracia excesiva: los empleadores se quejaban de tantos gastos y papeleos, cuando tradicionalmente llegaba la mano de obra a su destino, sin ningún costo para ellos y con el único problema de que eran indocumentados. Un problema adicional fue la medida paternalista que el gobierno Mexicano impuso a los braceros, al obligarlos a realizar un ahorro del $10 \%$ de sus salarios en bancos norteamericanos, que a su vez serían depositados en el banco Nacional de Crédito agrícola de México. Como se sabe, nunca se llegó a devolver el total del ahorro a los trabajadores. Por otra parte la burocracia involucrada también tenía sus propios conflictos, discrepancias, filias y fobias. En México, la secretaria de relaciones exteriores negociaba a nivel bilateral, la secretaria de gobernación negociaba a nivel interno con las entidades y los gobernadores, mientras la secretaría de trabajo y previsión contrataba y llevaba a cabo el proceso. También intervenían otras agencias como por ejemplo los Ferrocarriles Nacionales que se encargaban del transporte de braceros, la secretaría de salud que hacía los exámenes médicos y los militares que controlaban que los contratados tuvieran en orden su cartilla militar. En Estados Unidos, el conflicto se dio entre varias agencias gubernamentales: el Departament of Labor (DOL), aliado con los sindicatos que saboteo de diversas maneras al programa Bracero; el inmigration an Naturaliation Service (INS) que paradójicamente se constituyó en su acérrimo defensor, así como el departamento de Agricultura que apoyaba a los agricultores que requerían de mano de obra. Las diferencias y zancadillas entre dependencias de los gobiernos de ambos países añadieron una serie de problemas suplementarios a la administración del programa.

- El problema de los centros de reclutamiento: Otra fuente de diferencias bilaterales y problemas locales fue el lugar donde debería realizarse el reclutamiento. Para México la mejor opción era al interior del país, en las zonas de concentración de la población migrante y no en la frontera, como proponían los americanos y presionaban los empleadores, para ahorrarse los costos de transporte. México ya había experimentado la contratación fronteriza, con las casas de enganche, lo que había sido funesto. Por otra parte la contratación fronteriza alentaría la migración indocumentada y fomentaría la emigración de la escasa población que vivía en la franja. El reclutamiento pasó del Distrito Federal a las ciudades de Irapuato y Tlaquepaque, luego a Zacatecas, Chihuahua y monterrey, finalmente, en Empalme Sonora. En los últimos años se accedió a poner un centro de contratación en Mexicali que luego se cancelo. El gobierno mexicano perdió, con el tiempo, el control sobre esta situación y fue cediendo ante las presiones de los estadounidenses. 
- Impacto en el mercado de trabajo de ambos países: Habría que señalar que la contratación masiva de trabajadores temporales afectó necesariamente el mercado de trabajo de ambos países. En México, algunos gobernadores, como el de Guanajuato, se quejaron de la falta de trabajadores en sus entidades y culpaban al programa Bracero. En Estados Unidos sucedía lo contrario, la queja reiterada de los sindicatos era sobre el excedente de mano de obra barata que desplazaba al trabajador local.

- $\quad$ El contrato subordina al trabajador: una crítica recurrente al programa ha sido la conexión inexorable que existía entre el trabajador y el empleador. El bracero estaba contratado para ir a trabajar a un determinado lugar, rancho 0 localidad y no podía moverse, incluso si escaseaba el trabajo o, desde su punto de vista, las condiciones eran inadecuadas. Se dice que está característica le confirió al programa bracero un tinte de semi esclavitud. El trabajador estaba sometido a las condiciones del empleador y dado el carácter temporal y la dispersión de la mano de obra era prácticamente imposible ejercer algún tipo de control oficial, tanto de las autoridades mexicanas como norteamericanas

- Violaciones recurrentes al contrato de trabajo: Parece ser que las irregularidades más graves se dieron en el cultivo de Betabel, así como en el Estado de Texas. La practica del cultivo del Betabel dejaba al bracero temporadas libres en las que tenía que buscar otro trabajo, además las compañías dejaban pendientes pagos de las últimas semanas, por razones burocráticas, cuando los trabajadores debían salir antes de que llegará el invierno. En el Estado de Texas además de los problemas de discriminación, se tuvieron que modificar de manera imperativa, con coerción por parte del gobierno estadounidense, los mínimos salariales para que se ajustaran con los acordados en el programa braceros y con lo que se pagaba en otros lugares.

El programa funcionó, a pesar de que durante varios años México aplicó un veto explicito al Estado de Texas, por prácticas de discriminación. El veto de poco servía, porque los tejanos seguían contratando indocumentados. Cuando ambas partes no pudieron llegar a un acuerdo en 1954, y se canceló el programa de manera unilateral, México tuvo que aceptar que era improcedente la pretensión de impedir por la fuerza la salida de sus ciudadanos y Estados Unidos tuvo que aceptar que no era conveniente llevar un programa de bracero unilateral. Esta operación conocida como "el secado de mojados"8no era otra cosa que una medida de presión coyuntural que no pudo durar mucho tiempo. Incluso después de la operación Wetback ${ }^{9}$, en la que se deportaron a cerca de un millón de indocumentado, el gobierno mexicano supo recomponer las relaciones y renegociar el programa. Obviamente, con todas estas presiones México y los trabajadores iban perdiendo posiciones, pero el convenio se prorrogó por diez años más. (Durand y Massey, 2003)

\footnotetext{
${ }^{8}$ Se denominaba "mojados" a aquellos trabajadores mexicanos indocumentados

${ }^{9}$ La operación Wetback establecida en 1954 consistió en crear una campaña para reportar a todos los trabajadores indocumentados que estaban en Estados Unidos. Al no ser legales en el país extranjero los trabajadores mexicanos eran eximidos del servicio público que el gobierno estadounidense ofreciera, por ejemplo educación y servicios médicos.
} 


\section{Repensando la teoría a través de la historia}

Si realizamos el ejercicio de reflexión de poner en dialogo las distintas explicaciones teóricas, en torno a las migraciones, que se han presentado en este trabajo, con el caso de las migraciones laborales mexicanas, ocurridas en el marco del Programa Braceros, lo primero que notamos es que la postura denominada neoclásica, resulta insuficiente para explicar este fenómeno. En la explicación neoclásica la migración aparece como una elección guiada por una racionalidad utilitarista supuestamente ahistórica y universal. De esta forma se comete una falacia economicista naturalizándose un fenómeno inminentemente social, sin lograr abarcar su verdadera complejidad.

La teoría neoclásica corresponde a un entorno idealizado en que las personas se mueven de manera libre y espontáneamente, guiados por la búsqueda de sus intereses y maximización de utilidad. Por el contrario, a través del recorrido histórico de la dinámica de movilidad poblacional, que se da entre México y Estados Unidos, se puede apreciar claramente como en el campo laboral y migratorio dependiendo de las diferentes coyunturas políticas y económicas, se han establecido entre México y Estados Unidos "aperturas"( como es el ejemplo del programa braceros) o "cierres" ( como han sido las deportaciones de mexicanos) para que exista un flujo de mano de obra de un país al otro.

A diferencia de otras variables demográficas, como pueden ser la mortalidad y la fecundidad, la migración implica la noción de espacio. Por lo tanto la concepción que se adopte sobre la noción de espacio condicionará la manera en que se interprete la migración. No debe olvidarse que lo espacial es un constructo influido por las maneras de interpretar lo social, por lo tanto la noción de espacio no deberá ser tomada de manera neutra y ahistórica. El espacio debe ser concebido como una construcción social y no dado de forma natural. Como toda construcción social la noción de espacio se irá transformando a través del tiempo adquiriendo distintas significaciones comprensibles a la luz de determinados momentos históricos.

Podemos decir que lejos de considerar al espacio como una entidad que preexista a lo social, se debe tener en cuenta que los procesos sociales moldean lo espacial. El mundo no debe ser interpretado como un mosaico de países cerrados y autónomos, sino más bien como una totalidad estructurada espacialmente por procesos históricos de centro y periferia. Estos procesos, simultáneamente opuestos y complementarios, producen una distribución espacial desigual del bienestar y generan subdesarrollo, junto a desarrollo, como dos caras de una misma moneda. En este sentido las explicaciones históricas estructurales parecerían adecuarse mejor, al caso concreto de las migraciones laborales transitorias, ya que las mismas lejos de reestablecer desequilibrios económicos, significaron el aporte de mano de obra barata para el crecimiento del sector agrícola de Estados unidos, y lejos estuvieron de contribuir a una verdadera solución del desempleo mexicano, por el contrario se puede afirmar que este tipo de situación llevo a que se amplíe aún más la brecha de desigualdad regional. 
Ahora bien dentro de este tipo de explicación teórica entre los determinantes del proceso migratorio, se pone énfasis en la estructura económica y socialabordándose la temática de las relaciones sociales de producción y los mecanismos de dominación capitalista- mientras las relaciones con otros procesos como los culturales o los demográficos o la incidencia de los motivos individuales pasan inadvertidos. Así aspectos como los culturales no son tenidos en cuenta a la hora de dimensionar estos tipos de fenómenos.

La teoría neoestructuralista de Gaudemar en términos de política económica, demuestra que los flujos de movilidad son lucrativos para las economías capitalistas y que los gobiernos pueden encauzar la movilidad. El programa Bracero es un ejemplo claro con respecto a la acción de los gobiernos sobre los flujos migratorios.

La influencia que poseen los factores políticos sobre las migraciones laborales puede verse de manera clara a través del cambio de composición que adquirieron las mismas cuando se paso del ya mencionado "sistema de libre enganche" al "programa Bracero", cambiándose de un tipo de movimiento conformado por familias enteras que iban a trabajar a Estados Unidos por largas estancias, a un tipo de migración individual, masculina y temporal.

Este último enfoque que se ha expuesto, denominado neo-estructuralista nos parece de los tres mencionados el más satisfactorio para abordar el caso histórico de la migración que constituyó el denominado programa Bracero. Ya que si bien reconoce que la movilidad responde a cierta estructura económica del sistema capitalista, no divorcia lo económico de factores culturales, demográficos y políticos a la hora de explicar los movimientos poblacionales. No obstante esto, lo que más resalta a la hora de estudiar las migraciones en perspectiva histórica, es la complejidad de las mismas, en relación a la multiplicidad de factores que se ponen en juego según varíe la coyuntura histórica.

De hecho, con respecto a la cuestión de separar factores económicos de factores políticos, o culturales, para explicar los motivos que originan los movimientos poblacionales, creemos que la misma se trata de un artificio que puede llegar a ser útil para el análisis de determinadas situaciones concretas, pero es necesario resaltar que en lugar de hablar de factores determinantes es más adecuado para la comprensión de estos procesos, hablar de múltiples dimensiones interrelacionadas, qué se ponen en juego de diversa manera, según varíe la coyuntura histórica .En el "programa Braceros" esto aparece de forma muy ilustrativa, ya que existe en determinado momento coyuntural una clara demanda de mano de obra mexicana por parte de Estados Unidos, esta demanda a su vez va acompañada de un acuerdo político bilateral firmado por ambos gobiernos, así como tampoco se puede dejar de lado cuestiones culturales que tuvieron como consecuencia actitudes discriminatorias contra los trabajadores mexicanos.

Por último consideramos otra noción importante para la comprensión del movimiento de flujos poblacionales a través del espacio, esta es la noción de "frontera" no solamente porque la identificación de límites permite diferenciar un 
territorio de los espacios circunvecinos, sino también porque las significaciones y funciones sociales de las fronteras resultan un elemento clave para la comprensión de la configuración territorial. En el caso de las migraciones descriptas en este artículo, pensamos que la noción de frontera implica una fuerte carga simbólica, que excede el significado netamente económico de la movilización de mano de obra, pasar de México a Estados Unidos simboliza pasar al llamado "primer mundo", pasaje que implica una promesa de prosperidad económica y social; este pasaje al primer mundo representa mucho más que la obtención de un empleo para aquellos que lo efectúan, la migración laboral implica el tránsito de diferentes identidades sociales contextualizadas en el entramado de relaciones que establecen múltiples actores en un momento sociohistórico puntual.

\section{Bibliografía}

(2003) Arango, Joaquín. La explicación teórica de las migraciones: luz y sombra. En Migración y Desarrollo, en www.migracionesydesarrollo.org.

(1997) Bulmer- Thomas, Víctor "Las economías latinoamericanas, 1929-1939" en Leslie Bethell (editor) tomo II "Historia de América Latina" Critica, Barcelona.

(1980) Cardoso, Lawrense. Mexican Emigration to the United States 18971931, Tucson, University of Arizona Press.

(1984) Díez Canedo Ruíz, Juan. La migración indocumentada de México a los Estados Unidos: Un nuevo enfoque, Fondo de cultura Económica, México.

(1995) Domenach, Hervé. Las migraciones. Dirección general de publicaciones Universidad Nacional de Córdoba.

(2007) Durand Jorge. El programa Bracero (1942-1964). Un Balance crítico. En Migración y desarrollo, en www.migracionydesarrollo.org.

(2005) Durand Jorge y Arias Patricia. La vida en el norte. Historia e iconografía de la migración México- Estados Unidos. El colegio de San Luis, Guadalajara, 2005

(2003) Durand Jorge y Douglas Massey. Clandestinos. Migración MéxicoEstados Unidos en los albores del siglo XXI. Purrua, México.

(1976) Gaudemar, Jean Paul. Mobilidade do trabalho e acumulacao do capital. Editorial Estampa, Lisboa. 
(1970) Harris, J y Todaro, H "Migration, unemployment, and development: A two sectors analisis". Americans economics Review.

(1983) Keely, Charles "The failure of United States immigration policy" en America's new immigration law: origins, rationales, and potential consequences. Center for Us La Jolla, California.

(1986) López Castro Gustavo "Migración temporal a Estados Unidos en una comunidad rural Mexicana". En Se fue a volver. Seminario sobre migraciones temporales en América Latina. PISPAL-CIUDAD-CENEP. El Colegio de México.

(2000) Meyer Lorenzo, "De la estabilidad al cambio" en: "Historia general de México", El Colegio de México, Centro de estudios históricos, México.

(1986) Pachano, Simón. "Se fue a volver". En Se fue a volver. Seminario sobre migraciones temporales en América Latina. PISPAL-CIUDAD-CENEP. EI Colegio de México.

(1998) Portes Alejandro y Boroez Jozef. Migración contemporánea. Perspectivas teóricas sobre sus determinantes y sus modalidades de incorporación. En Malgesini Gerardo (comp.) Cruzando Fronteras. Migraciones en el sistema mundial. Madrid: Crítica.

(1989) Stern, Claudio "La industrialización y la migración en México" en Peter Peek y Guy Standing, Políticas de Estado y migración. Estudios sobre América Latina y el Caribe .Colmex México.

(2000) Verduzco Gustavo. La migración mexicana a Estados Unidos: estructuración de una selectividad histórica. Conapo. México. 